\title{
Life Cycle Costing of Alternative Value Chains of Biomass Energy for Cooking in Kenya and Tanzania
}

\author{
Abigael Okoko $\mathbb{D}^{1,2}$ Susanne Wymann von Dach, ${ }^{3}$ Juergen Reinhard, \\ Boniface Kiteme, ${ }^{1}$ and Samuel Owuor ${ }^{2}$ \\ ${ }^{1}$ Centre for Training and Integrated Research in Arid and Semi-Arid Lands Development, Nanyuki, Kenya \\ ${ }^{2}$ Department of Geography and Environmental Studies, University of Nairobi, Kenya \\ ${ }^{3}$ Centre for Development and Environment, University of Bern, Switzerland \\ ${ }^{4}$ Quantis International, Zurich, Switzerland
}

Correspondence should be addressed to Abigael Okoko; abbyokoko.81@gmail.com

Received 14 March 2018; Revised 25 July 2018; Accepted 30 September 2018; Published 1 November 2018

Academic Editor: Nuri Azbar

Copyright (C) 2018 Abigael Okoko et al. This is an open access article distributed under the Creative Commons Attribution License, which permits unrestricted use, distribution, and reproduction in any medium, provided the original work is properly cited.

\begin{abstract}
In near future, wood-based biomass energy will remain the main cooking energy for households in East Africa, especially for poor households due to its availability and affordability. Alternative biomass fuels however exist. Economic viability of these alternatives is important due to its potential to influence their adoption and sustained use. This research evaluates the economic efficiency of firewood, charcoal, biogas, jatropha oil, and crop residue briquettes value chains in the rural-urban contexts of Kitui, Kenya, and Moshi, Tanzania, using Life Cycle Costing (LCC) methodology. LCC helps to identify areas along the value chains where costs occur and where improvements are feasible. Jatropha oil manual value chain has the highest cost. Firewood use with improved cook stoves is cost efficient. In Moshi's rural context, royalty fees increases cost of charcoal. Similarly, biogas in Kitui is less likely to be economically viable. Briquettes however have a competitive advantage over charcoal. The costs are dominated by fuel provision compared to cost of stoves. Therefore, payment schemes that improve adoption of improved stoves perceived as expensive will substantially reduce fuel cost. Enhancing availability and accessibility of technologies such as briquette presses will enhance biomass energy access and provide a source of income for households.
\end{abstract}

\section{Introduction}

Access to affordable, reliable, and sustainable energy is an essential prerequisite to achieving social and economic wellbeing as envisaged by Sustainable Development Goal 7 of the 2030 Agenda on affordable and clean energy and the Sustainable Energy for All Initiative (SE4All) [1]. The household energy sector in Africa mainly depends on wood-based energy since access to modern energy is delayed. Woodbased energy is easily accessible and affordable to the majority of poor households who live in the rural and urban areas. Moreover, wood-based energy can be produced locally [2] and is an important economic sector that provides income for the rural and urban households [3-5].

In Least Developed Countries (LDCs) and sub-Saharan Africa, wood is a primary source of fuel used for cooking relied upon by $85 \%$ of those who live in the rural areas [5].
On the other hand, wood provides energy for cooking for $38 \%$ and $30 \%$ of the urban population in LDCs and subSaharan Africa, respectively [5]. Biomass energy provides $68 \%$ of Kenya's overall energy requirement while petroleum accounts for about $22 \%$, electricity $9 \%$ and coal at less than $1 \%$ [6]. Charcoal, firewood, dung, and other traditional fuels are the main energy sources in Tanzania, with their use growing in absolute terms due to the increase in population and urbanisation [7-9]. In Tanzania, more than $85 \%$ of the population depend on wood-based energy for cooking [8, $10,11]$ and generate at least one billion dollars in revenue to the rural sector, therefore providing income and livelihoods particularly for the rural people, transporters, and urban traders [12].

However, the current production patterns and consumption practice of wood-based biomass energy, particularly charcoal, are considered to be unsustainable, contributing 
to degradation of natural resources, climate change, and impacting people's health $[13,14]$. There is an urgent need to identify alternative cooking fuels that are socially acceptable, ecologically, and economically viable with the potential to also mitigate indoor air pollution. Besides, more efficient wood-based energy value chains, alternative biomass energy options such as biogas, briquettes from farm residues, or jatropha oil, exist [14]. However, the economic viability of such alternative value chains has not yet been compared systematically. Elbehri et al. [15] argue that one way to assess economic viability of biomass energy is through identifying production costs. The overall profitability and consequently long-term economic viability depend on cost-reducing technological improvements and relative price competitiveness with alternative uses of feedstock [15]. According to the International Energy Agency-IEA Bioenergy [16], biomass energy must be as cheap as or cheaper than energy produced from competing energy sources. It is therefore important to evaluate the techno-economics of the entire value chain of biomass energy by comparing different supply chains [17]. The Life Cycle Costing (LCC) method allows the assessment of all costs related to a product or service, from its production to its consumption until its disposal and is a tool that can be adequately applied to monitor and manage costs over the product's life cycle [18]. The LCC of biomass energy allows understanding of the costs borne by the different actors along the biomass energy value chain and identifying the most cost-efficient biomass energy solutions; this is particularly important in the context of developing countries considering the continued reliance on biomass energy as a source of energy for cooking. Moreover, it helps to determine areas along the life cycle of biomass energy where highest costs occur and where intervention(s) could be applied to help improve the economic efficiency of biomass energy value chains for cooking. Such insights are key for informing all stakeholders including policy makers, the private sector, and households.

The study compares different biomass fuels (firewood, charcoal, biogas, jatropha oil, and crop residue briquettes) while focusing on their production and consumption technologies in two rural-urban contexts in Kenya and Tanzania, with the aim of identifying entry points for possible policy measures.

\section{Methodology}

2.1. Study Sites. The research was carried out in Kitui County (Kenya) and Moshi (Tanzania). An estimated 96.9\% of households in Kitui County use solid biofuels for cooking [19]. The majority (89\%) of households use firewood as their main source of energy, while $8 \%$ rely mainly on charcoal [20]. Firewood use dominates in rural areas, while charcoal use dominates in urban areas. On the other hand, adoption of improved firewood cook stoves remains very low despite efforts by government agencies, nongovernmental organisations and private sector to enhance their adoption. In Kitui Central the adoption rate of the maendeleo stove, Rocket stove, and envirofit stove by the rural households who largely depend on firewood was $22 \%, 12 \%$, and $4 \%$, respectively [21], despite their better performance related to health impact [22] and carbon footprint of the respective firewood value chain compared to the traditional three stones fireplace $[23,24]$. Kitui County has a population of about one million [19], $90 \%$ of which live in rural areas. With a population growth of about $2.1 \%$, it is expected that biomass energy use will increase, therefore increasing the pressure on natural resources, thereby aggravating land degradation [25].

Moshi, located in Kilimanjaro Region in Tanzania, has a population of about 700,000. Similar to Kitui County in Kenya, firewood and charcoal are the dominant sources of energy for cooking for rural and urban populations. In Moshi, about $80 \%$ of the rural population rely on firewood while $41 \%$ of the urban population rely on charcoal for cooking [26]. In Kilimanjaro Region, firewood, charcoal and biogas have substantial supply potentials whereas crop residue briquettes and jatropha oil have limited potentials [14]. Between 2002 and 2012, population growth in Kilimanjaro Region was $1.8 \%$. This is lower than the national average of $2.7 \%$ [26], but still high enough to cause increasing pressure on natural resources, including on wood for energy production.

\subsection{LCC Analysis}

Selection of Value Chains. The study considered value chains that differed with regard to the fuels, the technologies used for producing and consuming the fuels and the contexts. Fuels included were firewood, charcoal, biogas, briquettes from farm residues, and jatropha oil.

The selection of production and consumption technologies (Table 1) was done in two participatory workshops in Kitui and Moshi, in June 2014. Stakeholders, ranging from policy makers, researchers, to representatives of nongovernmental organisations, community-based organisation, and the private sectors identified those technologies that were deemed most promising in enhancing access to sustainable biomass energy options for cooking in the two research sites. We differentiated between the rural and urban contexts of Kitui and Moshi.

Assessment Steps. We followed the assessment steps according to Rebitzer and Nakamura [27] for each value chain. This study applies a functional unit of one meal cooked while assuming that it requires 5 mega joule (MJ) of net energy at the pot to cook one meal [28].

(1) Identification of the life cycle stages and defining assumptions (Table 2).

(2) Assignment of costs to the respective inputs of the life cycle stages per functional unit.

(3) Identification of additional costs of the life cycle stages that differ between the studied alternatives.

(4) Assignment of costs to additional processes identified in step (3). 
TABle 1: Considered biomass fuels and their production and consumption technologies in Kitui (KI) and Moshi (MO).

\begin{tabular}{|c|c|c|c|}
\hline Energy carrier & & Production technologies & Consumption technologies \\
\hline \multirow{2}{*}{ Wood-based biomass energy } & Firewood & None & $\begin{array}{l}\text { Unimproved stoves: Three stones } \\
\text { fireplace (KI, MO) } \\
\text { Improved stoves: maendeleo, rocket, } \\
\text { envirofit (KI); kuni chache, okoa (MO) }\end{array}$ \\
\hline & Charcoal & $\begin{array}{l}\text { Unimproved kiln: Basic earth mound kiln } \\
\text { (KI,MO) } \\
\text { Improved kiln: Improved basic earth kiln } \\
\text { (KI, MO) }\end{array}$ & $\begin{array}{l}\text { Unimproved charcoal stove (KI, MO) } \\
\text { Improved charcoal stove: Kenya Ceramic } \\
\text { Jiko (KI), Sazawa stove (MO) }\end{array}$ \\
\hline \multirow{3}{*}{ Alternative biomass energy } & Biogas & $\begin{array}{l}\text { Plastic biogas digester }(\mathrm{KI}) \\
\text { VACVINA biogas digester }(\mathrm{MO})\end{array}$ & Biogas stove (KI, MO) \\
\hline & Jatropha oil & $\begin{array}{l}\text { Manual jatropha oil press (KI, MO) } \\
\text { Diesel powered jatropha oil press (KI, } \\
\text { MO) }\end{array}$ & Jatropha oil stove (KI, MO) \\
\hline & Briquettes & $\begin{array}{l}\text { Manual briquette press (KI, MO) } \\
\text { Diesel powered briquette press (KI, MO) }\end{array}$ & Briquette stove (KI, MO) \\
\hline
\end{tabular}

(5) Calculation of the costs per life cycle stage by multiplying the cost per inputs from steps (2) and (4) with the absolute quantities of the process outputs.

(6) Aggregation of the costs of all life cycle stages over the complete life cycle. The life cycle cost results are given with reference to functional unit, i.e., in US\$/meal cooked for Kitui and Moshi, respectively.

In the rural context, the following life cycle stages were analysed: feedstock collection, feedstock processing, and consumption or use. In the rural areas, collection of fuel is mainly done by women and children who walk for hours [29]. Therefore, transportation of cooking fuel from the point of collection to the home using means such as bicycle, motorcycles or vehicles is excluded for the rural context. In this study, we however consider the time used to collect fuel for cooking in the feedstock collection phase. In the urban context, we analysed the use stage while considering the market price of the biomass fuels and the technology cost. The market price may fluctuate depending on the season and the supply-demand situation. In this study we use the dry season market price of the fuels which coincided with the time of our visit to the study sites.

Source of Data. The data used for the LCC analysis is based on field interviews with technology users $(n=47$, Kitui and $\mathrm{n}=31$, Moshi) on the price of technology and time used along the various stages of the value chains. In the urban context, data applied was also based on interviews conducted with households to obtain the price of cook stoves and biomass fuels. In addition, data used in modelling the life cycle costs of the selected biomass energy was obtained from literature sources (Table 2). However, in developing countries this is often met with obstacles, one of which is data scarcity and variability. In order to deal with data gaps, diverging assessments, we sought expert knowledge from Practical Action in Kenya and TaTEDO in Tanzania (as indicated in the footnotes of Table 2).

\section{Results and Discussion}

\subsection{Energy Costs per Meal Cooked in the Rural Context}

Feedstock Collection. Generally, feedstock collection largely contributes to the overall life cycle costs per meal cooked with firewood, ranging from $87 \%$ to $100 \%$ in Kitui, of the different value chain costs. In Moshi these costs range from $66 \%$ to $100 \%$. The use of improved technologies and the corresponding decrease in fuel input can help to reduce the cost per meal substantially (Figures 1 and 2). For instance, in Kitui there is a $30 \%, 55 \%$, and $57 \%$ reduction in the life cycle cost per meal cooked using the improved maendeleo stove, rocket stove, and envirofit stove, respectively, compared to the life cycle costs of the unimproved firewood value chain. Similarly, in Moshi, the life cycle cost per meal cooked reduces by $49 \%$ (kuni chache stove) and $69 \%$ (okoa stove) in the rural context compared to the unimproved firewood value chain.

Collection of firewood is done by children and women [29] whose labour is perceived as free leading to the presumption that using firewood for cooking is cheap.

Regarding the cost of wood harvesting for charcoal production, we notice that the improved efficiency of the kiln and the charcoal stoves $[23,24]$ directly translates into a positive economic impact [30] as considerably less wood is used for producing the same amount of charcoal $[23,31]$.

For biogas, the collection costs in Kitui are more than twice as high as in Moshi. This is due to the different grazing systems prevailing in these areas. In Kitui, we considered the collection costs for a free-range system of cattle rearing while in rural Moshi we assume zero grazing of cattle as is practiced due to Moshi's favourable agroclimatic conditions [32]. With an average of three cows per household, we estimate that one needs approximately 30 minutes to wash out the cow dung in a zero-grazing system into the biogas digester.

In general, feedstock collection of the jatropha oil manual value chain is $24 \%$ higher than the cost per meal in the jatropha oil diesel value chain. The collection of jatropha 


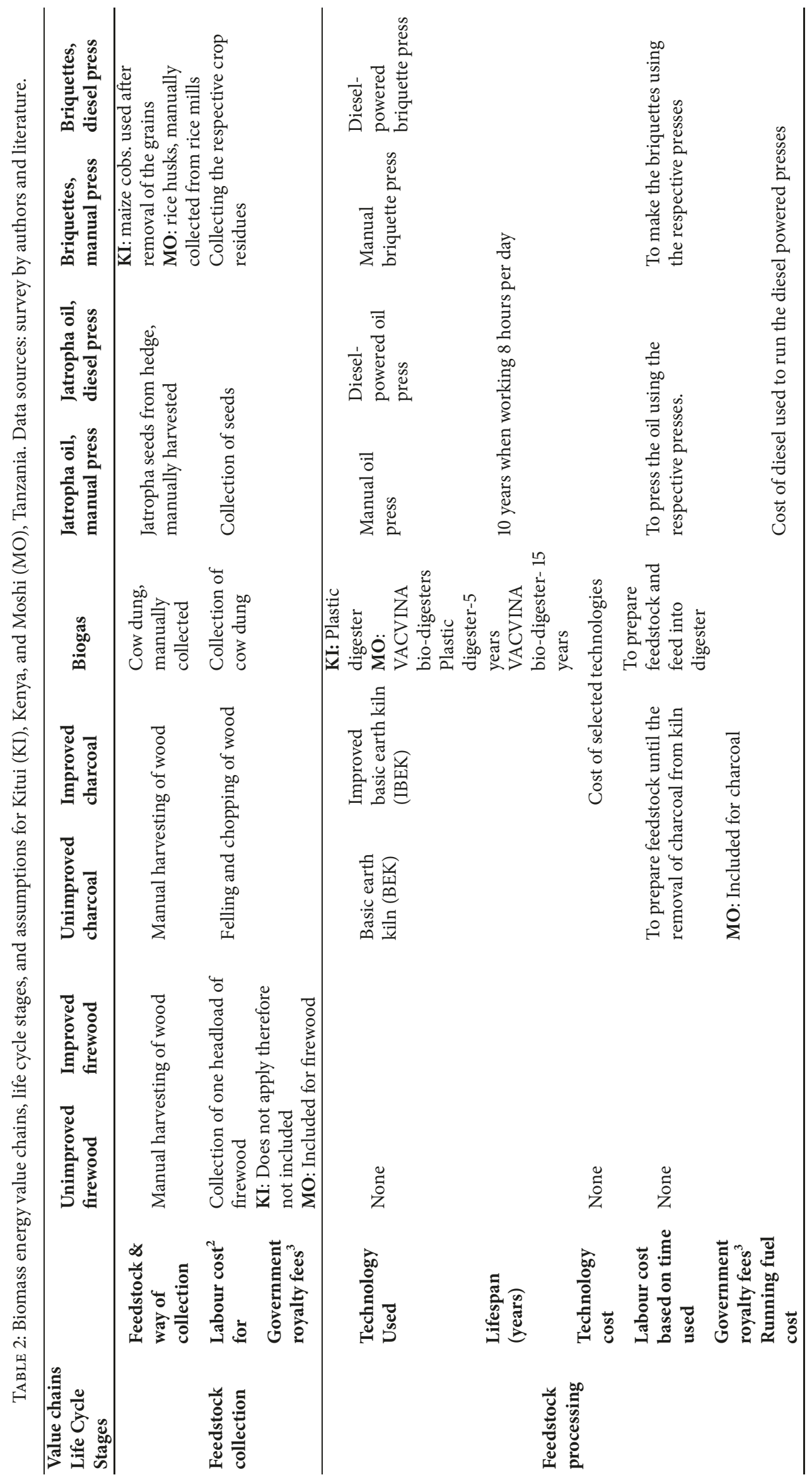




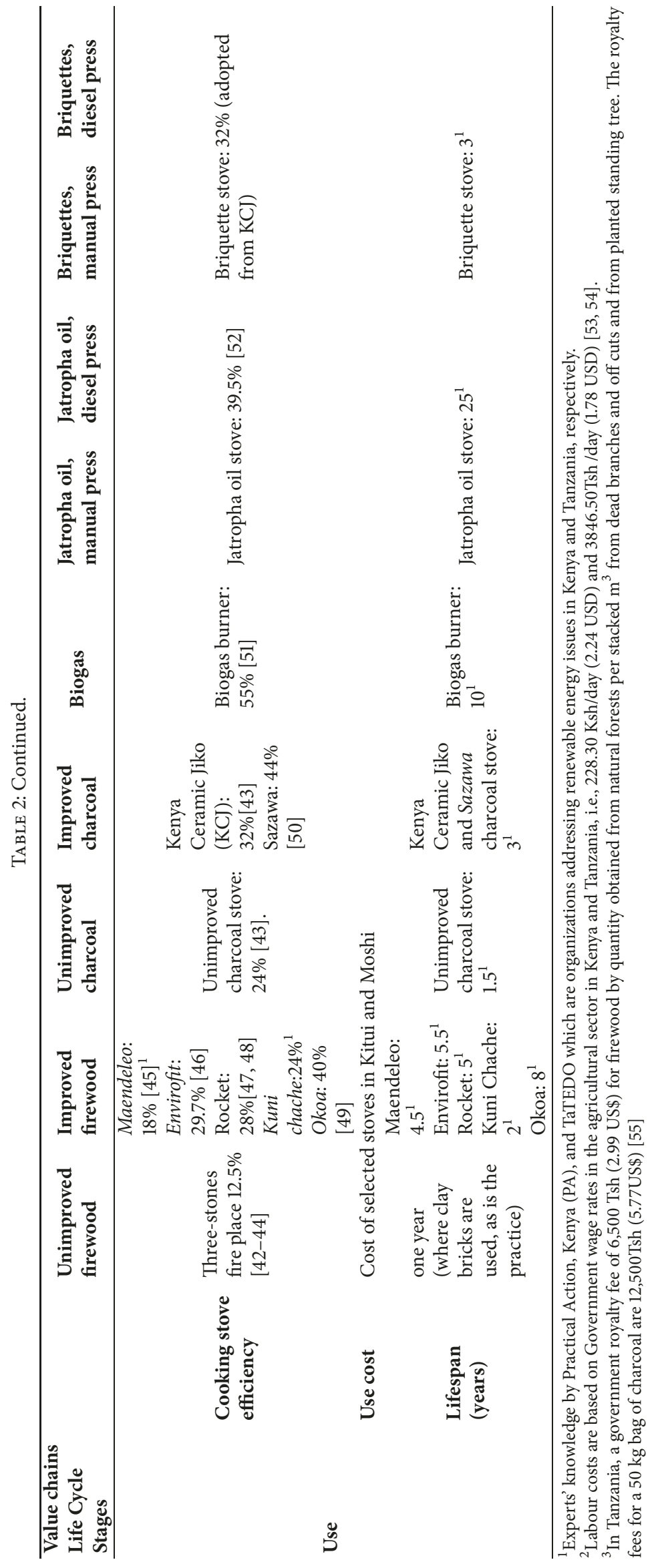




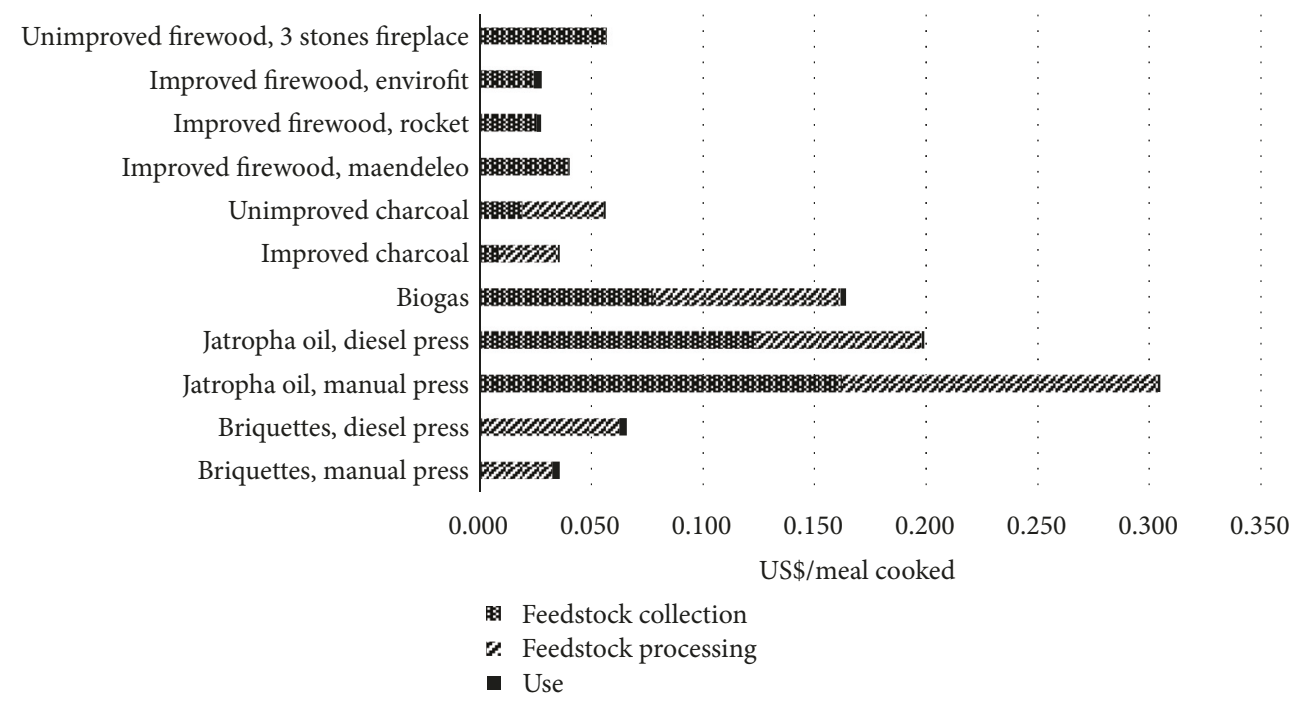

FIGURE 1: Life cycle costs per meal cooked (US\$) incurred over the different energy value chains in rural Kitui, Kenya.

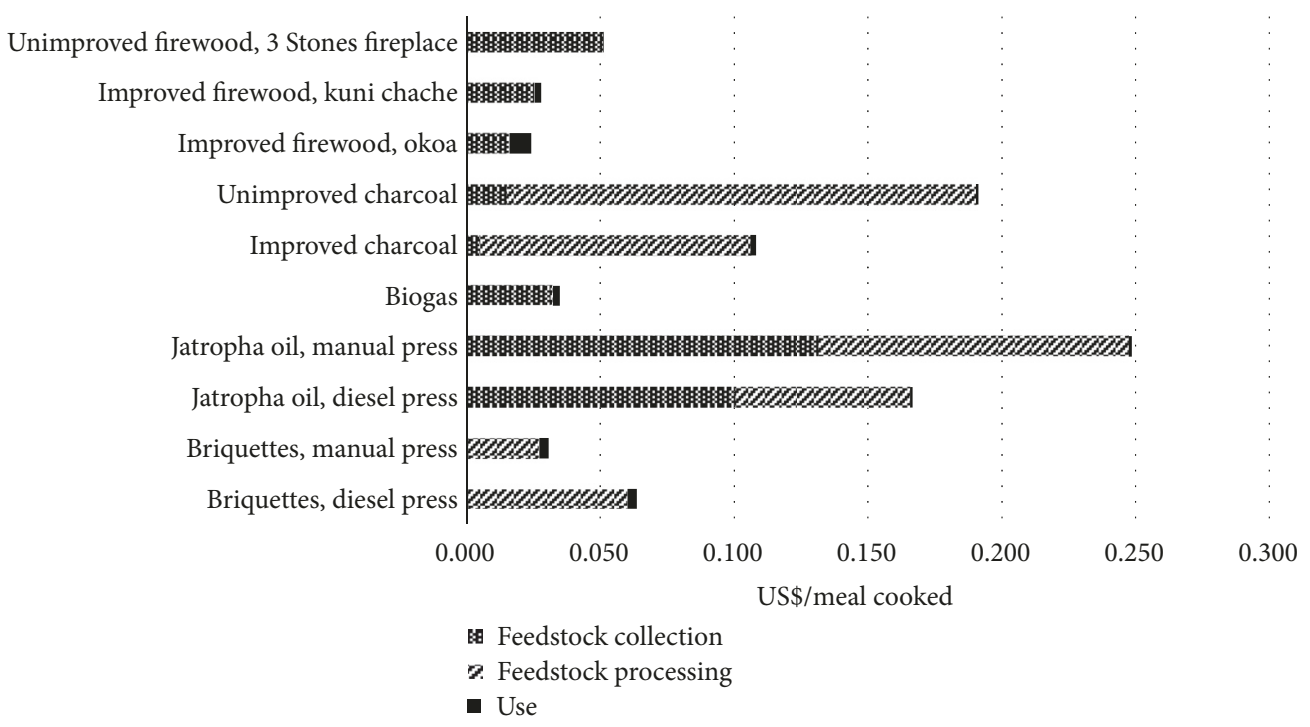

FIGURE 2: Life cycle costs per meal cooked (US\$) incurred over the different energy value chains in rural Moshi, Tanzania.

seeds is labour intensive, contributing up to $53 \%$ of the overall cost of jatropha oil manual value chain in Kitui and Moshi. Therefore, application of the diesel oil press, due to its better oil production efficiency $(80 \%)[33,34]$, reduces the labour input needed for an equivalent amount of jatropha oil. In general, jatropha oil manual value chain has the highest cost per meal cooked for feedstock collection stage among the selected biomass energy value chains in Kitui and Moshi, with that of the improved charcoal value chain being the least.

Despite the fact that collecting biomass fuel to provide cooking energy for rural families is an unpaid burden, women in the rural areas of developing countries devote valuable time and effort at the expense of education and income generation, to this work $[29,35]$. This study however indicates that when this labour is quantified and monetarised, the positive impact of utilising improved cook stoves [30] on feedstock collection is evident in economic terms, in addition to their contribution in reducing carbon footprint $[23,24]$ and health impacts.

Feedstock Processing. In both study sites feedstock processing costs vary substantially. For instance, since firewood is used as it is without any further conversion, it therefore has no cost per meal cooked for this stage while jatropha manual press and the unimproved charcoal value chains have the largest feedstock processing costs per meal in Kitui and Moshi, respectively.

In Kitui, feedstock processing contributes $70 \%$ to the overall cost per meal in the unimproved charcoal value chain. Labour cost has a large share of contribution in both charcoal value chains. However, the cost of labour in the unimproved value chain exceeds that of the improved value chain by 
up to $33 \%$. The inclusion of the royalty fees in Moshi has a significant influence on the cost of feedstock production with the unimproved charcoal having a cost of $0.2 \mathrm{US} \$ / \mathrm{meal}$ cooked while that of the improved charcoal value chain is to $0.1 \mathrm{US} \$ /$ meal cooked. Of these costs, the royalty fees contribute $80 \%$ and $74 \%$ to the overall cost of feedstock production (charcoal production) for the unimproved and improved charcoal value chains, respectively. $95 \%$ of the royalty fees go to the central government while $5 \%$ of the total royalty fees go to the local government. In the rural context of Kitui, feedstock production stage of the unimproved charcoal value chain has a life cycle cost of 0.04 US $\$ /$ meal cooked while that of the improved charcoal value chain is $0.03 \mathrm{US} \$ /$ meal cooked. To conclude, the life cycle cost of charcoal production in Moshi exceeds that of Kitui by up to $80 \%$.

In the rural context of Kitui, feedstock processing for biogas production contributes $51 \%$ to the overall cost per meal cooked of the biogas value chain. In the context of freerange cattle keeping system as considered for Kitui, it takes a person an average of one hour to prepare the feedstock and feed it into the digester. Of the overall cost per meal, the largest cost is allocated to the labour at $92 \%$ while only $8 \%$ is allocated to the cost of the plastic biogas digester. In the rural context of Moshi, feedstock processing for biogas production contributes $8 \%$ of the total life cycle costs along this value chain, which is wholly allocated to cost of the VACVINA digester. This is because in a zero-grazing system, it is possible that the cattle shed is directly connected to the VACVINA biodigester and therefore during cleaning the feedstock is already channelled into the biodigester, thus allocating all the labour to the feedstock collection phase. Although the cost of installing a single biogas digester is high, posing a major challenge to adoption of biogas technology [36], the unit of digester per meal reduces when its lifespan, estimated at 15 years for the VACVINA biodigester, is considered.

In the rural context of Kitui and Moshi, feedstock processing in the jatropha oil manual value chain is $47 \%$ and $44 \%$ higher than that of the jatropha oil diesel press value chain in Kitui and Moshi, respectively. In both cases, labour cost plays a significant role.

Similarly, the allocation of labour in the crop residue briquette manual value chain is quite significant: $72 \%$ and $67 \%$ in Kitui and Moshi, respectively. However, in the diesel value chain, the contribution of labour is considerably low compared to the manual value chain. It contributes only $4 \%$ to the overall life cycle cost of briquette processing, while that of the press is considerably high, contributing $72 \%$ and $73 \%$ in Kitui and Moshi, respectively. In general, feedstock processing stage in the diesel press value chain is larger than that of the manual press value chain by $49 \%$ and $56 \%$ in Kitui and Moshi, respectively. Ngusale et al. [37] estimated that the manual briquette press produces $12 \mathrm{~kg} /$ hour compared to $100 \mathrm{~kg} / \mathrm{hour}$ by the diesel powered briquette press. As such the diesel briquette press significantly reduces the labour cost per meal cooked. However, this high labour cost of the manual briquette press is offset by the higher cost of the diesel press machine; 294 US\$ and 1,469 US\$, respectively, in addition to the fuel cost which contribute $23 \%$ of the feedstock processing stage. The net effect is a higher cost of feedstock processing by the crop residue diesel press value chain as compared to the manual press value chain.

Use. As generally observed, the use stage in the biomass energy value chains studied in the rural context has the least contribution to the cost per meal cooked. This contribution however may vary among different value chains. In this stage, the cost per meal cooked of the selected value chains includes the cost of the stove but excludes that of fuel. Inclusion of the cost of fuel would amount to double counting of upstream costs (i.e., cost of feedstock collection, feedstock processing, and transport of the biomass energy).

In the rural context of both study sites, use of the three stones fireplace presents the lowest cost per meal cooked contributing $<1 \%$ to the overall cost per meal of the unimproved firewood value chain. This is also confirmed by Afrane and Ntiamoah [38]. In some instances, households use clay bricks since natural stones are not available. This study indicates that even when the clay bricks are used, the cost per meal cooked remains quite insignificant. By contrast, the cost per meal cooked with improved firewood stoves is higher by $83 \%$ (maendeleo stove), $90 \%$ (kuni chache stove), 95\% (rocket stove), and 97\% (envirofit stove and okoa stove) largely attributed to the higher purchasing price of the improved stoves. Comparatively, the envirofit and the okoa stoves have higher purchasing/installation costs than the rest of the firewood stoves studied. For instance, at the time of study, the average price of the envirofit was 39 US\$ while the installation of the okoa stove in Moshi required up to 138 US\$.

3.2. Energy Costs per Meal Cooked in the Urban Context. In the urban context analysis, we included the cost of the studied biomass fuels and the costs of the selected stoves. The fuel cost adapts the market price of the fuel since biomass fuels in the urban context are bought from the local markets. This cost of the fuels assumes that the upstream costs (feedstock collection, processing, and transportation) are already included in their market price and therefore the need to avoid double counting of costs. Therefore the urban context analysis is based on the type of fuel and stove. For instance, the market price of jatropha oil and briquettes is used not considering the production technology.

Generally, the use cost per meal cooked in Kitui and Moshi is considerably lower compared to that of the biomass fuels (Figures 3 and 4). In the urban context of Kitui and Moshi (Figures 3 and 4), cooking with the three stones fire place is the most expensive among the firewood value chains.

Although firewood is generally considered as the cheapest cooking fuel [38], this study indicates that the cost per meal cooked reduces with improvement in thermal efficiency of the firewood cook stove. This finding is supported by the study by Adkins et al. [39] stating that fuel savings are realised by use of improved stoves. In Moshi market, $1 \mathrm{~kg}$ of charcoal retails at 500 Tsh (0.23 US\$) while a bundle of firewood is sold at 4,000 Tsh (1.85 US\$). The average weight of a headload of firewood varies between $15 \mathrm{~kg}$ and $26 \mathrm{~kg}[29,40,41]$. However we apply an average weight of $17 \mathrm{~kg}$ based on weight taken at the site. The fuel required per meal, determined by the stove efficiency and fuel energy content, is $2.2 \mathrm{~kg}$ of wood 


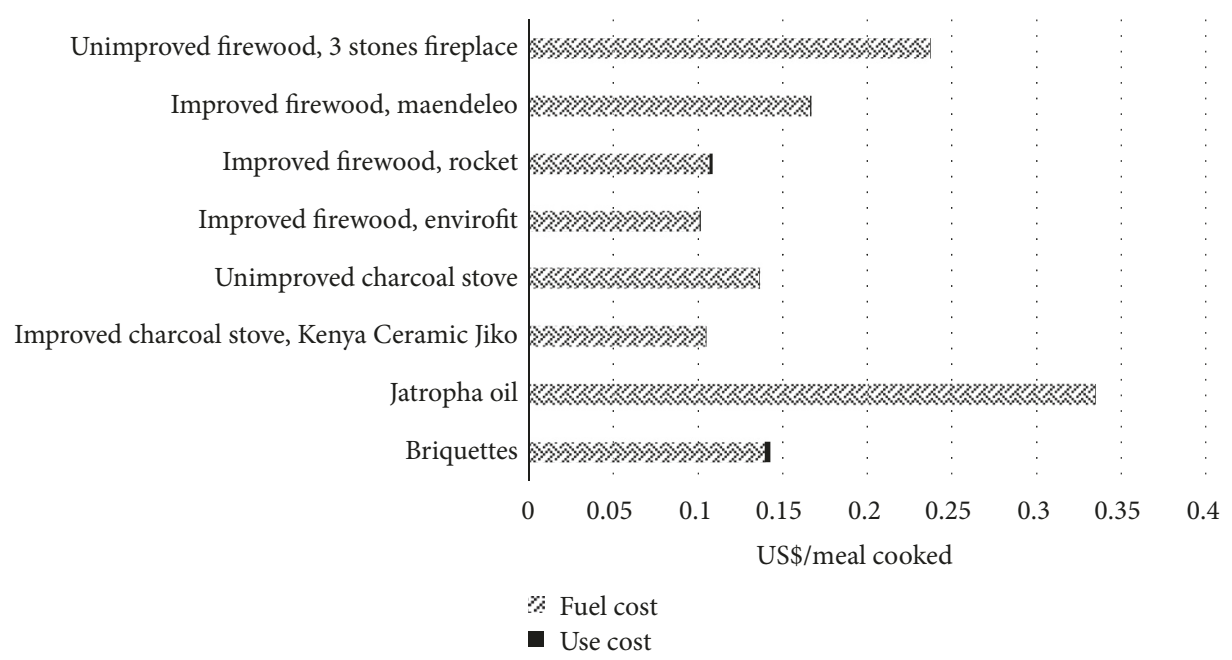

FIGURE 3: Life cycle costs per meal cooked (US\$) for the different energy value chains in urban Kitui.

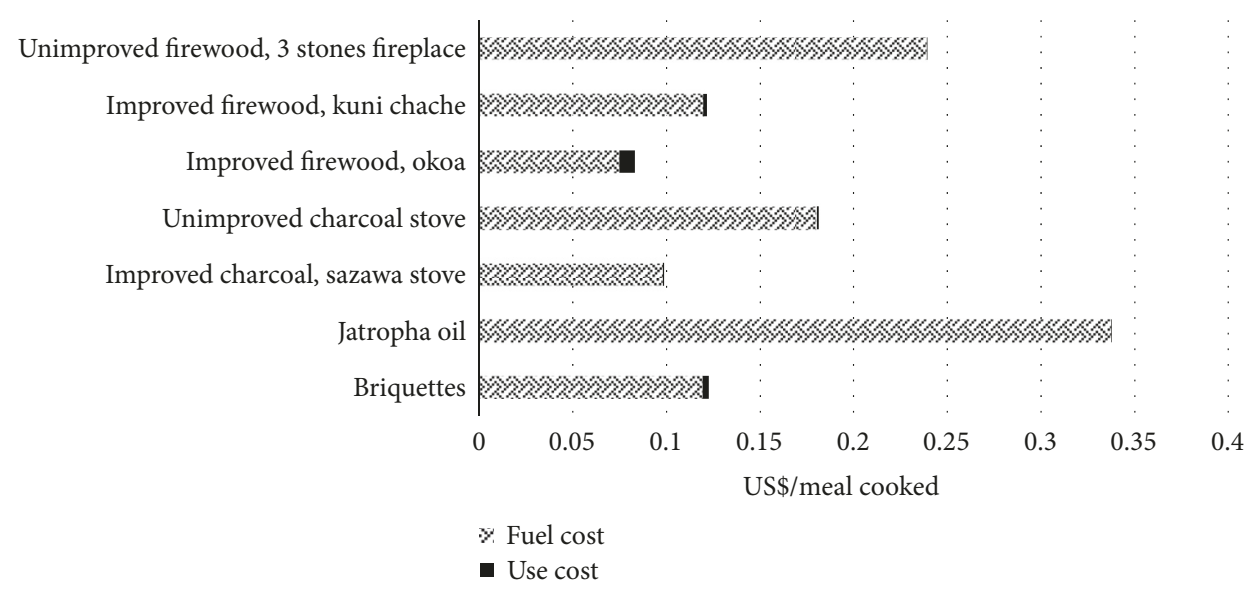

FIGURE 4: Life cycle costs per meal cooked (US\$) for the different energy value chains in urban Moshi.

per meal cooked for unimproved firewood value chain while that of unimproved charcoal value chain is $0.8 \mathrm{~kg}$ of charcoal per meal cooked. Use of the unimproved stoves results to consumption of more headloads of firewood and bags of charcoal therefore increasing household expenditure on fuel. However, use of improved cook stoves such as the okoa stove has the potential to substantially reduce (Figure 4) household expenditure on cooking fuel.

Of great interest is the gradual decline of the cost per meal cooked with improved stoves (firewood and charcoal) when spread across the lifespan, compared to the cost of fuel (Figures 3 and 4) as opposed to their lump sum initial purchasing price. This is an indication that adequate cost mechanisms or incentives have the opportunity to influence adoption of improved biomass energy technologies that are otherwise expensive, making them inaccessible [29, 35]. Important to note is that the economic costs of high reliance on biomass for cooking are substantial [56]. Additionally, continued reliance on unimproved stoves by the rural and urban poor households would potentially lead to overexploitation of biomass resources due to their limited fuel saving capacity consequently increasing forest degradation [57-59]. Furthermore, traditional biomass use has negative impacts on health with approximately 600,000 lives lost each year in sub-Saharan Africa due to exposure to biomass smoke [56].

\subsection{Overall Comparison}

Life Cycle Stages

(i) The use costs are minimal (cost of stoves) compared to the fuel costs (collection, processing, or fuel costs in urban areas) in all sites and contexts.

(ii) Labour investments play a crucial role in cooking energy, however, as long as this work is adequately considered and paid.

Comparison of Fuels

(i) The most cost-efficient biomass energy source is firewood, if used with improved cook stoves with higher 
stove efficiencies. In addition, use of improved stoves potentially leads to a reduction in carbon footprints, fuel consumption, and indoor air pollutants, thus providing an environmental and health benefit [23, $60,61]$.

(ii) Charcoal shows a very mixed picture. The contextspecific differences are crucial. The results indicate that the royalty fee in Moshi is not visible in the market price. This can be due to the fact that the charcoal available in the market in Moshi is not produced locally due to the law prohibiting charcoal production within Kilimanjaro Region since 2012. Charcoal available in markets in Moshi is often transported from other regions such as Korogwe and Kilindini in Tanga region, Simanjiro and Kiteto in Manyara region etc. (Oral interview with the Kilimanjaro Regional Natural Resources Office and Tanzania Forest service).

(iii) From an economic point of view the results indicate that briquettes are in a price range that makes them competitive with charcoal. Studies have however shown very low rates of adoption of briquettes [21, 62] despite the fact that they can be used by households as a supplement to other biomass fuels like wood adding to the energy mix [63]. In addition briquettes have the potential to lower greenhouse gas emission (carbon footprints), help alleviate environmental degradation compared to unsustainable charcoal, and increase access to renewable energy [64]. Enabling policy and institutional frameworks and favourable market structures are important in enhancing accessibility and availability of briquette technologies and briquettes [62].

(iv) The cost of biogas is however dependent on the technology and the type of livestock herding. Among the alternative biomass fuels, biogas is not as competitive as briquettes in Kitui's rural context due to the constraints of dung collection, which in the long run is not feasible in addition to other factors. As reported by Lwiza et al. [65], the labour that sustains the adoption of biogas is often dependent on family members, and more so children. Absence of this labour thus makes its adoption difficult. However in Moshi's rural context, adoption of the zero-grazing system of cattle rearing could provide a desirable source of fuel adding to the lists of options for the population.

(v) Jatropha has the highest costs in both sites and context, even if it is processed more efficiently using a diesel press.

\section{Comparison between Sites and Contexts}

(i) Overall, we find a similar pattern between Kitui and Moshi. However, the cost of charcoal in Moshi is complicated by the inclusion of royalty fees, making the cost of charcoal higher than in Kitui. Biogas in Kitui is not attractive due to the cattle herding system which requires a lot of labour. The cost of the biogas technology also plays a role in influencing the total cost of the biogas value chain in the rural context of both study sites. For instance, the high unit cost of the VACVINA biogas digester significantly contributes to the feedstock processing in Moshi while that of the plastic biogas digester is insignificant.

(ii) The market prices in the urban areas do not reflect the picture of the rural area, i.e., rural costs plus transportation cost. The explanation is more complex as market mechanisms play a role; scarcity of supply, origin of charcoal (in Moshi for instance charcoal is mainly from outside the region), and taxes (both legal and illegal) [66] which are passed on to the consumer.

\section{Conclusion}

Assessments of all costs of biomass based energy solutions, including labour costs, along the whole value chain can provide crucial information to decision-makers and practitioners about the economic viability of different options and also about entry points for reducing energy costs. Moreover, comparing the LCC of biomass energy solutions in two different contexts reveals the importance of context-specific factors that can make a substantial difference in the cost of cooking energy. Looking at the different life cycle stages, the study shows that the costs contribution of improved stoves to the total costs per meal are not important, since they seldom exceed 5\%. This indicates that with appropriate payment schemes, the higher costs of improved stoves should not be a limiting factor when it comes to their adoption. The costs per meal are dominated by the fuel provision (feedstock collection and processing). Bearing this in mind, any increase in stove efficiency will have a large effect on fuel costs and therefore reduce costs per meal (and also environmental impact) significantly. It is therefore necessary that relevant payment schemes to support the adoption of improved stoves are introduced or enhanced; for instance, introduction of a "flat rate", where poor households receive a modern stove (free of charge) and only have to pay a monthly allowance for the required fuel input (which is far less than the fuel costs associated with a low-efficiency stove). The in-depth knowledge about the economic costs of biomass energy solutions is certainly pertinent. However, the energy costs are only one, even though important, factor in determining households' decisions about sustainable cooking energy solutions in Eastern Africa.

\section{Data Availability}

All data and materials used in this research paper are housed at Centre for Training and Integrated Research in Arid and Semi-Arid Lands Development (CETRAD).

\section{Disclosure}

Abigael Okoko is an environmental scientist, currently working on the environmental and economic performance of alternative biomass energy value chains in Kitui, Kenya, and 
Moshi, Tanzania, as part of her Ph.D. at the University of Nairobi, Department of Geography and Environmental Studies. Susanne Wymann von Dach is senior research scientist at the Centre for Development and Environment, University of Bern. Her work focuses on innovation process for sustainable development. Boniface Kiteme is a senior research scientist at the Centre for Training and Integrated Research in Arid and Semi-Arid Lands Development (CETRAD), Nanyuki, Kenya. His work focuses on research activities that inform environmental policies. Juergen Reinhard is a Life Cycle Analyst at Quantis International, Zurich, Switzerland. Samuel Owuor is a senior lecturer at the University of Nairobi, Department of Geography and Environmental Studies.

\section{Conflicts of Interest}

The authors declare that they have no conflicts of interest.

\section{Authors' Contributions}

Abigael Okoko conducted the research in Kenya and Tanzania, analysed the data, and wrote the paper. Susanne Wymann von Dach coordinated the research project in Kitui and Moshi and was involved in internally reviewing the paper and providing comments for improvements. Boniface Kiteme coordinated work package one under which this research falls in addition to supervising the candidate. Juergen Reinhard was involved in internally reviewing the work and providing comments for improvements. Samuel Owuor provided supervision to the candidate.

\section{Acknowledgments}

The research presented was part of research project entitled "Prospects for Biomass Energy in East Africa" (Project IZ01Z0_146875), which was part of the Swiss Programme for Research on Global Issues for Development (r4d programme) implemented and funded jointly by the Swiss Agency for Development and Cooperation (SDC) and the Swiss National Science Foundation (SNSF).

\section{References}

[1] UN, Transforming our world: the 2030 Agenda for Sustainable Development: Sustainable Development, UN, Geneva, Switzerland, 2015.

[2] D. Rajagopal and D. Zilberman, "Review of environmental, economic and policy aspects of biofuels," Berkeley, 4341, 2007.

[3] R. J. Butz, "Changing land management: A case study of charcoal production among a group of pastoral women in northern Tanzania," Energy for Sustainable Development, vol. 17, no. 2, pp. 138-145, 2013.

[4] GoK, "Analysing the charcoal value chain in Kenya," Final Report, GoK, Nairobi, Kenya, 2013.

[5] G. Legros, I. Havet, N. Bruce, and S. Bonjour, The Energy Access Situation in Developing Countries: A Review Focusing on the Least Developed Countries and Sub-Saharan Africa, New York, NY, USA, 2009.

[6] GoK, Draft National Energy Policy, GoK, Nairobi, Kenya, 2015.
[7] L. P. Lusambo, "Household energy consumption patterns in Tanzania," Journal of Ecosystem and Ecography, vol. 01, no. S5, article 007, 2016.

[8] M. Felix and S. H. Gheewala, "A review of biomass energy dependency in Tanzania," Energy Procedia, vol. 9, pp. 338-343, 2011.

[9] A. L. D’Agostino, J. Urpelainen, and A. Xu, "Socio-economic determinants of charcoal expenditures in Tanzania: Evidence from panel data," Energy Economics, vol. 49, pp. 472-481, 2015.

[10] H. Sosovele, "Policy challenges related to biofuel development in Tanzania," Africa Spectrum, vol. 45, no. 1, pp. 117-129, 2010.

[11] NBS, "National Environment Statistics Report, 2017 (NESR, 2017)," Tech. Rep., National Bureau of Statistics, Dar es Salaam, Tanzania Mainland, 2017.

[12] K. Sander, C. Gros, and C. Peter, "Enabling reforms: Analyzing the political economy of the charcoal sector in Tanzania," Energy for Sustainable Development, vol. 17, no. 2, pp. 116-126, 2013.

[13] T. H. Mwampamba, "Has the woodfuel crisis returned? Urban charcoal consumption in Tanzania and its implications to present and future forest availability," Energy Policy, vol. 35, no. 8, pp. 4221-4234, 2007.

[14] R. Bär, A. Heinimann, and A. Ehrensperger, "Assessing the potential supply of biomass cooking fuels in Kilimanjaro region using land use units and spatial Bayesian networks," Energy for Sustainable Development, vol. 40, pp. 112-125, 2017.

[15] A. Elbehri, A. Segerstedt, and P. Liu, Biofuels and The Sustainability Challenge: A Global Assessment of Sustainability Issues, Trends and Policies for Biofuels and Related Feedstocks, Rome, Italy, 2013.

[16] IEA Bioenergy, Economic Sustainability of Biomass Feedstock Supply, IEA Bioenergy, Finland, 2011.

[17] B. Batidzirai, Design of sustainable biomass value chains: Optimising the supply logistics and use of biomass over time, Ultrecht University: The Netherlands, Ultrecht University, The Netherlands, 2013.

[18] K. Lichtenvort et al., "Introduction: history of life cycle costing, its categorization, and its basic framework," in Environmental Life Cycle Costing, D. Hunkeler, K. Lichtenvort, and G. Rebitzer, Eds., pp. 1-16, Society of Environmental Toxicology and Chemeistry (SETAC), Florida, Fla, USA, 2008.

[19] U. Wiesmann, B. Kiteme, and Z. Mwangi, Socio-Economic Atlas of Kenya: Depicting the National Population Census by County and Sub-Location, CDE, Bern, Switzerland, 2016, KNBS, Nairobi. CETRAD, Nanyuki.

[20] E. Ngugi, G. M. Kamula, K. Sivi-Njonjo, J. Lakin, A. Nadim, and Z. L. Wanyama, Exploring Kenyas Inequality: Pooling Apart or Pooling Together?Kitui County, Nairobi, Kenya, 2013.

[21] M. Emily, Socio-Economic Factors Influencing Adoption of Improved Biomass Energy Technologies in Rural And Urban Households in Kitui, Kenya, University of Nairobi, Nairobi, Kenya, 2015.

[22] A. Ehrensperger et al., "What future for cooking with solid biomass? The benefits of improved stoves and micro-gasifiers. ProBE Policy Brief 1," Nairobi, Kenya and Bern, Switzerland.

[23] N. MacCarty, D. Ogle, D. Still, T. Bond, and C. Roden, "A laboratory comparison of the global warming impact of five major types of biomass cooking stoves," Energy for Sustainable Development, vol. 12, no. 2, pp. 56-65, 2008.

[24] A. Okoko, J. Reinhard, S. W. von Dach et al., "The carbon footprints of alternative value chains for biomass energy for cooking in Kenya and Tanzania," Sustainable Energy Technologies and Assessments, vol. 22, pp. 124-133, 2017. 
[25] GoK, First County Integrated Development Plan 2013- 2017: Planning for Sustainable Socio-Economic Growth and Development', Kitui, 2014.

[26] TNBS, 2012 Population and Housing Census', Dar es Salaam, 2013.

[27] G. Rebitzer and S. Nakamura, "Environmental life cycle costing," in Environmental Life Cycle Costing, D. Hunkeler, K. Lichtenvort, and G. Rebitzer, Eds., pp. 35-57, Society of Environmental Toxicology and Chemeistry (SETAC), Florida, Fla, USA, 2008

[28] J. Reinhard et al., "More out of less: future scenarios of clean cooking solutions in East Africa. Policy Brief 2," Nabyuki, Kenya and Bern, Switzerland, 2017.

[29] WEO, Focus on Key Topics; Energy for Cooking in Developing Countries, 2006.

[30] J. Hafner, G. Uckert, F. Graef et al., "A quantitative performance assessment of improved cooking stoves and traditional threestone-fire stoves using a two-pot test design in Chamwino, Dodoma, Tanzania," Environmental Research Letters, vol. 13, no. 2, Article ID 025002, 2018.

[31] H. Hoffmann, G. Uckert, C. Rybak, F. Graef, K. Sander, and S. Sieber, "Efficiency scenarios of charcoal production and consumption - a village case study from Western Tanzania," Food Security, vol. 10, no. 4, pp. 925-938, 2018.

[32] E. Ulicky, J. Magoma, H. Usiri, and A. Edward, "Improving smallholder livelihoods: Dairy production in Tanzania," Tropical Grasslands-Forrajes Tropicales, vol. 1, no. 2, pp. 244-248, 2013.

[33] R. Henning, The Jatropha Booklet: A Guide to The Jatropha System and Its Dissemination in Africa, Weissensberg, Germany, 2000.

[34] FACT Foundation, The Jatropha Handbook: from Cultivation to Application, FACT Foundation, The Netherlands, 2010.

[35] Africa Renewable Energy Access Program, Wood-based biomass energy development for Sub-Saharan Africa: Issues and approaches, Africa Renewable Energy Access Program, Washington, Wash, USA, 2011.

[36] R. Muvhiiwa, D. Hildebrandt, N. Chimwani, L. Ngubevana, and T. Matambo, "The impact and challenges of sustainable biogas implementation: moving towards a bio-based economy," Energy, Sustainability and Society, vol. 7, no. 1, 2017.

[37] G. K. Ngusale, Y. Luo, and J. K. Kiplagat, "Briquette making in Kenya: Nairobi and peri-urban areas," Renewable \& Sustainable Energy Reviews, vol. 40, pp. 749-759, 2014.

[38] G. Afrane and A. Ntiamoah, "Analysis of the life-cycle costs and environmental impacts of cooking fuels used in Ghana," Applied Energy, vol. 98, pp. 301-306, 2012.

[39] E. Adkins, E. Tyler, J. Wang, D. Siriri, and V. Modi, "Field testing and survey evaluation of household biomass cookstoves in rural sub-Saharan Africa," Energy for Sustainable Development, vol. 14, no. 3, pp. 172-185, 2010.

[40] K. Openshaw, "Annex III - (b) Measuring fuelwood and charcoal, Wood fuel surveys," in Wood Fuel Surveys, 1983, http:// www.fao.org/docrep/q1085e/q1085e0c.htm\#annex.

[41] H. Hoffmann, G. Uckert, C. Reif, K. Müller, and S. Sieber, "Traditional biomass energy consumption and the potential introduction of firewood efficient stoves: insights from western Tanzania," Regional Environmental Change, vol. 15, no. 7, pp. 1191-1201, 2015.

[42] N. Jungbluth, "Life-cycle-assessment for stoves and ovens," UNS Working Paper 16, Zurich, Switzerland, 1997.
[43] J. Jetter, Y. Zhao, K. R. Smith et al., "Pollutant emissions and energy efficiency under controlled conditions for household biomass cookstoves and implications for metrics useful in setting international test standards," Environmental Science \& Technology, vol. 46, no. 19, pp. 10827-10834, 2012.

[44] W. T. Wiskerke, V. Dornburg, C. D. K. Rubanza, R. E. Malimbwi, and A. P. C. Faaij, "Cost/benefit analysis of biomass energy supply options for rural smallholders in the semi-arid eastern part of Shinyanga Region in Tanzania," Renewable \& Sustainable Energy Reviews, vol. 14, no. 1, pp. 148-165, 2010.

[45] GVEP International, "Improving the performance of locally manufactured biomass cook stoves in Kenya," Tech. Rep. UNF13-475, 2015.

[46] GACC, "SuperSaver Wood GL (M-5000)," http://catalog .cleancookstoves.org/stoves/35.

[47] P. Scott, J. Vineyard, and A. / Gtz, "New Rocket Stove Designs for Central and Southern Africa".

[48] KIRDI, "Cookstove evaluation report," Tech. Rep., Nairobi, Kenya, 2015.

[49] GACC, “Test results: kuniokoa," http://catalog.cleancookstoves .org/test-results/821.

[50] G. R. John, R. A. Mulungu, and L. Wilson, Bioenergy technologies development and promotion. Volume 1: Test analysis and findings for improved charcoal stoves, Dar es Salaam, Tanzania, 1995.

[51] G. Afrane and A. Ntiamoah, "Comparative Life Cycle Assessment of Charcoal, Biogas, and Liquefied Petroleum Gas as Cooking Fuels in Ghana," Journal of Industrial Ecology, vol. 15, no. 4, pp. 539-549, 2011.

[52] H. Huboyo, S. Tohno, P. Lestari et al., "Comparison between Jatropha curcas seed stove and woodstove: Performance and effect on indoor air quality," Energy for Sustainable Development, vol. 17, no. 4, pp. 337-346, 2013.

[53] United Republic of Tanzania, "Labour Institution Act. CAP 300," Tech. Rep., United Republic of Tanzania, Dar es Salaam, Tanzania, 2013.

[54] GoK, “The Labour Institutions Act No. 12. Kenya Gazette Supplement No. 91," Tech. Rep., GoK, Nairobi, Kenya, 2015.

[55] United Republic of Tanzania, "The Forest Act. CAP 323. Supplement No. 29: The Forest Amendment Regulations," Tech. Rep., United Republic of Tanzania, Dar es Salaam, Tanzania, 2017.

[56] F. Lambe, M. Jürisoo, H. Wanjiru, and J. Senyagwa, Bringing Clean, Safe, Affordable Cooking Energy to Households across Africa: An Agenda for Action, Stockholm Environment Institute for the New Climate Economy, Stockholm, Sweden, 2015.

[57] M. F. Chagunda, C. Kamunda, J. Mlatho, C. Mikeka, and L. Palamuleni, "Performance assessment of an improved cook stove (Esperanza) in a typical domestic setting: implications for energy saving," Energy, Sustainability and Society, vol. 7, no. 19, pp. 1-9, 2017.

[58] I. K. Okuthe and E. N. Akotsi, "Adoptions of improved biomass cook stoves by households: an example from Homabay county," International Journal of Humanities and Social Science, vol. 4, no. $9,2014$.

[59] C. Okello, S. Pindozzi, S. Faugno, and L. Boccia, "Development of bioenergy technologies in Uganda: A review of progress," Renewable \& Sustainable Energy Reviews, vol. 18, pp. 55-63, 2013.

[60] J. J. Jetter and P. Kariher, "Solid-fuel household cook stoves: Characterization of performance and emissions," Biomass \& Bioenergy, vol. 33, no. 2, pp. 294-305, 2009. 
[61] WHO, Fuel for Life: Household Energy and Health, WHO, Geneva, Switzerland, 2006.

[62] T. H. Mwampamba, M. Owen, and M. Pigaht, "Opportunities, challenges and way forward for the charcoal briquette industry in Sub-Saharan Africa," Energy for Sustainable Development, vol. 17, no. 2, pp. 158-170, 2013.

[63] A. Ehrensperger, S. Wymann von Dach, R. Bär, A. Okoko, and A. Lannen, "A burning challenge: making biomass cooking fuels sustainable in East Africa," in CDE Policy Brief, p. CDE, Bern, Switzerland, 2018.

[64] EEP/SEA, "Analysing briquette markets in Tanzania, Kenya and Uganda,” Tech. Rep., EEP/SEA, Gauteng, South Africa, 2013.

[65] F. Lwiza, J. Mugisha, P. N. Walekhwa, J. Smith, and B. Balana, "Dis-adoption of Household Biogas technologies in Central Uganda," Energy for Sustainable Development, vol. 37, pp. 124132, 2017.

[66] T. H. Mwampamba, A. Ghilardi, K. Sander, and K. J. Chaix, "Dispelling common misconceptions to improve attitudes and policy outlook on charcoal in developing countries," Energy for Sustainable Development, vol. 17, no. 2, pp. 75-85, 2013. 

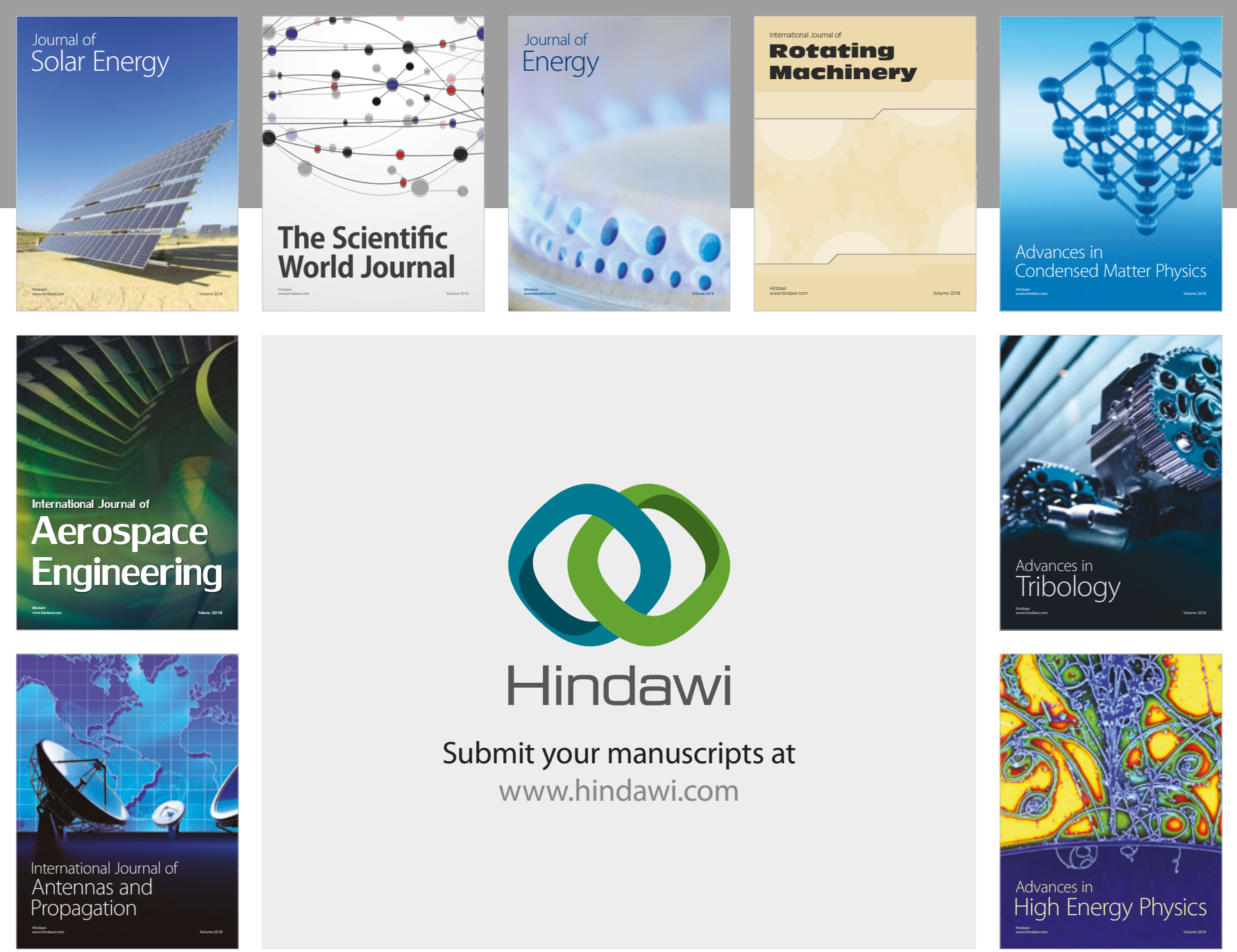

Submit your manuscripts at

www.hindawi.com
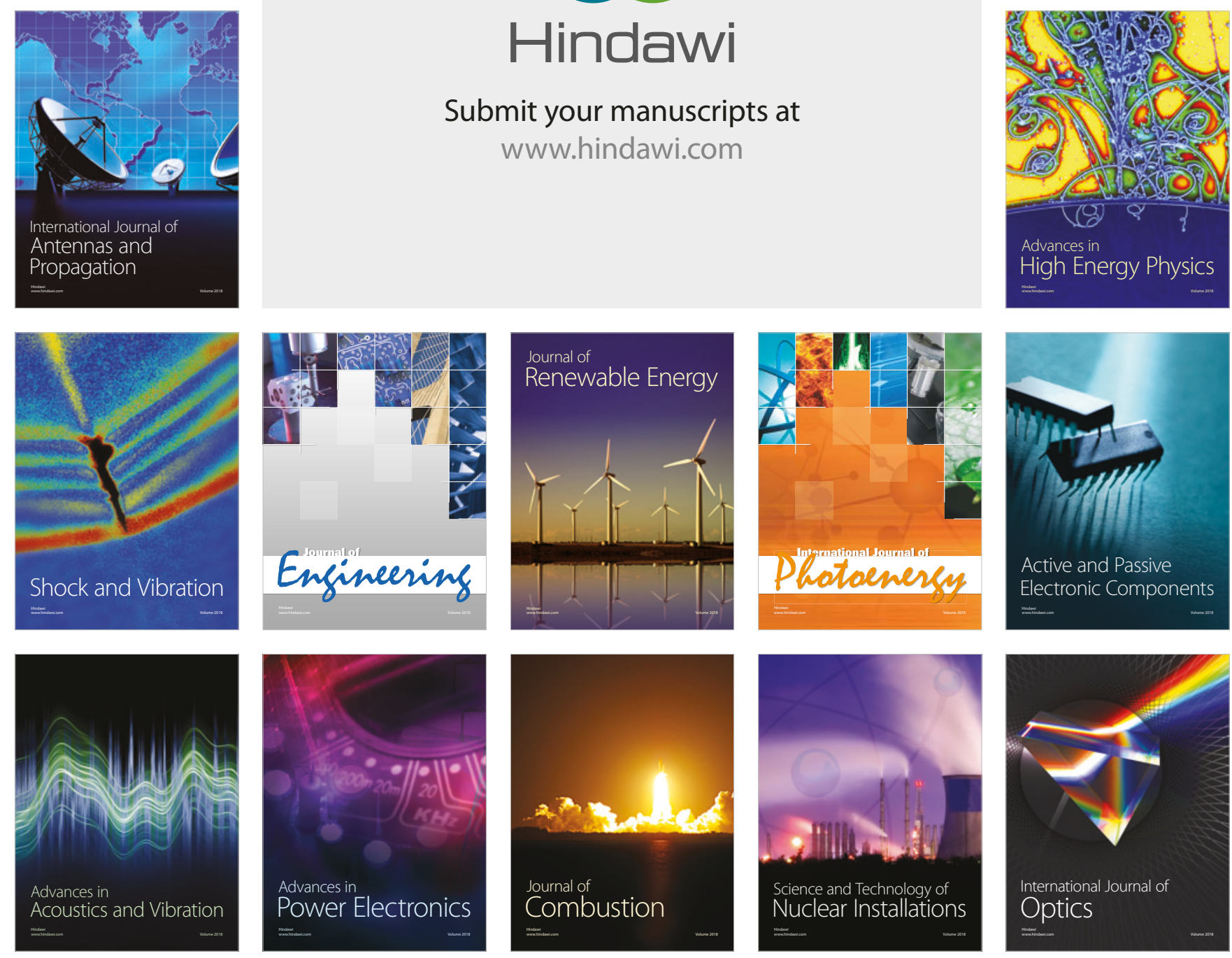